\title{
Examining the relationships between individual's time use and activity participations with their health indicators
}

\author{
Yusak O. Susilo ${ }^{1}$ (1) Chengxi Liu $^{1}$ \\ Received: 15 October 2016 / Accepted: 21 April 2017 /Published online: 4 May 2017 \\ (C) The Author(s) 2017. This article is an open access publication
}

\begin{abstract}
Purpose Using a three-week household activity-travel survey, this paper explores the relationship between individuals' selfreported physical, mental and social health conditions and their time allocation for different types of in-home and outof-home time activities.

Methods A path model is developed to investigate the roles of activity-travel time use on the self-reported health conditions, while the socio-demographics and residential environment characteristics are also considered.

Results The model results reveal heterogeneous impacts of different types of activities and intensities on individual's self-reported health conditions. This study, however, did not find evidence of positive relationship between cycling and walking and self-reported physical health condition, which has been found in many developed countries. Presumably this is because in developing countries like Indonesia the individuals who walk and cycle are likely to be a part of economically disadvantaged groups who have less awareness to their own health conditions.

Conclusion Beside activity and travel time use factors, age and working status were found significantly affecting the selfreported health conditions, regardless of respondents' gender and income. Neighbourhood characteristics, such as population
\end{abstract}

This article is part of Topical Collection on Transport poverty, equity and environmental justice

Yusak O. Susilo

yusak.susilo@abe.kth.se

Chengxi Liu

chengxi@abe.kth.se

1 Department of Transport Science, KTH Royal Institute of Technology, Teknikringen 72, 10044 Stockholm, Sweden density, are also found positively correlated to self-reported respondents' physical, social and mental health conditions.

Keywords Day-to-day variability $\cdot$ In-home and out-of-home activity participations $\cdot$ Physical mental and social health indicators $\cdot$ Indonesia

\section{Introduction}

In the last decade, there has been a surge in the studies that investigate the positive health effects from the use of physically active travel modes such as walking and cycling. These active travel modes have gained attentions from both transport/urban planners and public health experts because they are considered as of low-emissions, space efficient, and can positively contribute to the travellers' physical health [1-4]. Hallal et al. [5] estimated that today, globally, $30 \%$ of adults were lack of physical activities. Together with an energy-dense diet, insufficient physical activities would lead to obesity epidemic, a condition that is associated with cardiovascular diseases, type 2 diabetes, cancer and impaired mental health [6-9].

Based on this believe, many governments are promoting cycling and walking as an alternative to reduce the health risk that comes out from sedimentary lifestyle (e.g. $[10,11])$. The physical health impacts from walking and cycling have now started to be taken into account in various governments' cost-benefit analysis processes. Various methods were proposed to measure and compare the health impacts of active travel. Typical health impacts models that were used to assess the impact of these physically active transport activities are based on hypothetical scenarios with mostly linear correlation assumption on changes in the amount of active travel and the health gains (e.g. $[12,13])$. Systematic reviews on the 
impacts of physically active travel modes to the travellers' health conditions can be seen at Mueller et al. [9] and Wanner et al. [14], for example. Most of previous studies agree to each other that higher participations in physically active travel activities, such as walking and cycling, correlate with a better physical health condition in general. The expected impacts, however, vary across different socio-demographic groups, and some are contradicting with each other. For example, some studies such as Vogel et al. [15] highlighted the benefit of physically active travel for older people since the activity is expected to substantially reduce the absolute risk for chronic degenerative disease. Some studies (e.g. [15-22]) also argued that the risk would outweigh the detriments of traffic incidents and air pollution exposure. However, Mueller et al. [9] also pointed out that the argument that older people benefit differently from the same physically active exposure than younger people remains inconclusive. Woodcock et al. [17, 23] argue that older people would benefit a larger mortality risk reduction from physically active participation compared to younger people, whereas Götschi et al. [4] explained that the impacts of physically active travel is also a function of the current conditions of the travellers. 30 min cycling would have relatively smaller impacts to the travellers who have been cycling everyday compared to the ones who hardly cycle at all in their live. Mueller et al. [9] concluded that the benefits of physically active travel participation "are sensitive to the contextual setting and population parameters. Health impact estimations depend on baseline prevalence of active travel participation, baseline exposure to health pathways and the general status of the population."

Moving to the context of the analysis, most previous studies measured the health effects of active travel based on one day (or "average day") observation of a given individual's travel or aggregate, cross-section, based observations. Observing a physically active travel on the given day for a given individual does not necessarily mean he/she has a physically active travel routine on a day-to-day basis (thus difficult to measure his/her baseline exposure to a healthy lifestyle). Furthermore, many studies put a lot of emphasise on a particular indicator of active travel, i.e. frequency or amount of walking and cycling, as individual's main travel mode on their main trip leg. However, in reality, most travellers are multimodal travellers and, in many cases, the last-mile and short trips modes have a higher frequency and intensity than a regular, medium-long distance, routine trips. Furthermore, since individual needs and desires are not constant from day-to-day, an individual's activity-travel pattern is neither totally repetitious nor random every day [24-29]. The repetitiveness of mode choices highly correlates with the accessibilities of the activity locations, whereas different types of activity have different patterns of repetition. Moreover, most of the previous studies tend to overlook the benefits and/or dis-benefits that the individuals gain from and the trade-off between their daily in-home and out-of-home activities. This can lead to an over or under estimated benefits of physical active travel to individual's well-being and also to their physical health conditions, e.g. trade-off between an active travel and an active training in a gym. Therefore, it is important to quantify the benefits that an individual gains from both physically activity travel and their day-to-day in-home and out-of-home activities in order to better understand the real value of physically active travel behaviours; not only to physical health, but also to individual's social and mental health.

To contribute to these research gaps, using a 3-weeks travel diary which was collected in the Bandung Metropolitan Area, Indonesia, this study investigates the relationships between travellers' physically active travel participation with the type and intensity of their daily activities and their self-assessed physical, mental and social health conditions. This study not only investigates the impacts of day-to-day variability of different types of in-home and out-of-home activities to individual's health related aspects, but also reveals such behaviours, correlations, and trends in the context of developing country, i.e. Indonesia, which, to authors' knowledge, has never been studied in the past.

In the next section, the study area is described and so as the used datasets. It is followed by a section which presents the descriptive analyses on individual's different time use allocation on different day towards different type of in-home and out-of-home activities. Section 4 describes the estimation results on the influence of one's activity participations with ones' selfreported physical, mental, social health conditions. Conclusions will be presented in Section 5.

\section{The study area and data description}

\subsection{The Bandung metropolitan area (BMA)}

The Bandung Metropolitan Area (BMA) is the capital of the Province of West Java and is approximately $200 \mathrm{~km}$ or two to three hours' drive south of Jakarta. With its 
conurbation, BMA population is about 7.89 million people, in a 3382.89 square $\mathrm{km}$ size area and is the second largest metropolitan area in Indonesia after the Jakarta Metropolitan Area. As a typical city in developing countries, the BMA has a very relaxed or unplanned mixed and monocentric land use, congested road networks, and poor public transport networks and services [30, 31]. Road congestion and the low performance of public transport/ paratransit encourage the BMA's travellers to use motorcycles to reduce their travel costs and time [32-35]. At the same time, they usually have more choices within a closer range in which to conduct their activities along their travel routes, due to the highly mixed land use configurations.

\subsection{The 2013 BMA dataset}

The BMA dataset contains household, physical activity and lifestyle, individual's subjective characteristics, time-use and activity diary, and subjective well-being data. The survey involved 732 individuals and 191 households from all over BMA for 21 consecutive days. The household data section contains household composition, individual's perception about how far his/her accommodation from city centre, public and transportation facilities, and build environment variables. Time-use and activity diary survey captured twenty-three in-home and out-of-home activity classifications, travel duration and mode characteristics, and multitasking activities for adults, young adults and children above 7 years old. In this study, time-use activity participation was classified into several groups of mandatory and discretionary activities.

In this study, the mandatory activities are categorised into: (1) in-home and (2) out-of-home mandatory activities. Out-ofhome mandatory activities were defined as activities to meet other individuals or materials with high degree temporal and spatial fixity at a location outside home base such as working at workplace locations, studying at school, having business meeting and dropping off/picking up children to/from school locations. Activities undertaken at home for fulfilling individual's basic needs such as sleeping, eating and personal care is defined as in-home mandatory activities which have high degree of temporal and spatial fixity [36].

Discretionary activities were categorised into (1) maintenance and (2) leisure activities. Discretionary activities for satisfying household and personal physiological and biological needs [37] were defined as maintenance activities. This includes in-home maintenance activities, such as housekeeping and nursing activities, as well as out-of-home maintenance activities such as grocery shopping, health treatment activities and other service activities (such as going to bank, post office) [38]. As leisure activities were discretionary activities undertaken within individual's available time either inhome or out-of-home for satisfying cultural and physiological needs [37]. This includes entertainment (such as watching TV, listening music/radio, reading magazines/ newspapers and accessing the Internet), social and family activities (such as meeting with family members and friends, visiting relatives/friends and undertaking sport, leisure, and voluntary activities and going on holiday). Multi-tasking activities is defined as concurrent activities contained primary and secondary activities [39, 40] for satisfying different needs and desires at the same time.

The questionnaire contained a section with healthrelated quality of life (QoL) questions and its potential influencing factors. Health-related QoL was developed based on SF-36 (Short-Form 36), one of the most widely used generic measures for health-related surveys [41]. It contains eight subscales that consider physical, social and mental health, which are measured in categories such as physical functioning (PF), limitations on role functioning according to physical health (RP), bodily pain (BP), general health $(\mathrm{GH})$, mental health $(\mathrm{MH})$, limitations on role functioning due to emotional problems (RE), social functioning (SF) and vitality (VT). As suggested by Suzukamo et al. [42], PF, RP and BP will be defined as physical health, RP, SF and RE as social health, and BP, GH, VT, SF, MH as mental health. The extra influence factors related to these questions include questions about health promoting activities, lifestyle and habits that coincide with the individual's time-use and activity diary, as well as the quality of residential environments [41]. This questionnaire also included detailed questions about physical activities in order to determine the average daily physical activities of individuals (as based on the International Physical Activities Questionnaire (IPAQ) (http://ipaq.ki.se) [43] that may influence their physical, social and mental health. More detailed description on the dataset and survey design can be found at Dharmowijoyo et al. [44]. The health indicators that were collected during the survey can be seen at Table 1 below and the profiles of the respondents can be seen at Table 2 .

\subsection{Descriptive analysis}

The travel and activity participation distribution across the observed period can be seen at Table 2. It is shown 
Table 1 Health survey questions

\begin{tabular}{|c|c|}
\hline Category & Description \\
\hline Physical activities & $\begin{array}{l}\text { 1. Body weight and height } \\
\text { 2. Vigorous activities as part of the individual's work/school activities and around the home } \\
\text { environment } \\
\text { 3. Moderate activities as part of the individual's work/school activities and around the home } \\
\text { environment } \\
\text { 4. Walking as part of the individual's work/school activities (excluding travel activities) } \\
\text { 5. Travel activities using a motorised mode/s } \\
\text { 6. Non-motorised transport activities (cycling and walking) } \\
\text { 7. Activities performed sitting down }\end{array}$ \\
\hline $\begin{array}{l}\text { Physical activities in leisure time as part of health } \\
\text { promoting activities }\end{array}$ & $\begin{array}{l}\text { 1. Objective and subjective measurement of walking } \\
\text { 2. Objective and subjective measurement of vigorous active exercise with and without } \\
\text { bodily collision, such as soccer, basketball, running, playing tennis/badminton, fast } \\
\text { cycling, aerobics, swimming, etc. } \\
\text { 3. Objective and subjective measurement of moderate active exercise with and without } \\
\text { bodily collision, such as light cycling, light swimming, light tennis/badminton, etc. }\end{array}$ \\
\hline $\begin{array}{l}\text { Social and communication activities with family } \\
\text { members and other people }\end{array}$ & $\begin{array}{l}\text { 1. Social and communication activities with other people, such as voluntary and } \\
\text { organisational activities, attending events and socialising at events } \\
\text { 2. Social and communication activities with other family members }\end{array}$ \\
\hline Lifestyle and health habits & $\begin{array}{l}\text { Eight types of habits: eating breakfast, enough sleep, eating balanced meals, smoking, } \\
\text { drinking alcohol, working less than nine hours each day, under stress/pressure } \\
\text { circumstances }\end{array}$ \\
\hline Health-related quality of life & $\begin{array}{l}\text { 1. Subjective measurement of an individual's health and comparison with the previous year } \\
\text { 2. Physical functioning } \\
\text { 3. Limitations on role functioning due to physical health } \\
\text { 4. Bodily pain } \\
\text { 5. General health } \\
\text { 6. Mental health } \\
\text { 7. Limitations on role functioning due to emotional problems } \\
\text { 8. Social functioning } \\
\text { 9. Vitality }\end{array}$ \\
\hline
\end{tabular}

in the table that individuals engage with different amounts of activity and trips on different day of the weeks. Whilst Friday, on average, is the busiest day in terms of activity engagement, travel time and number of trips and trip chaining, it also has the highest proportion of non-motorised mode trips. Consistent with case studies in developed countries (e.g., [45]), it was found that in Bandung individuals only spent around $4-5 \%$ of their time on travel. The data on Table 2 shows that in-home activities such as sleeping, in-home preparation and eating activities take more than $75 \%$ of individuals' daily time expenditure. This highlights the importance of understanding the physical activity intensity whilst one is at home and the trade-off between in-home and out-ofhome activities since in-home mandatory and working/ school activities act as an anchor and will limit the individual's ability to do other activities within his/her time-space on a given day [46-49].

The subjective health variables were categorised and three factor scores related to physical, mental and social health were derived from the factor analysis [44]. The derived factor scores are the estimated values of the factors in factor analysis. Detailed health-related Likert scale questions are designed to based on the International Physical Activities Questionnaire (IPAQ) (http://ipaq.ki.se) and these questions are used to derive the health scores. A complete list of the healthrelated Likert scale questions can be found in Table 1. Figure 1 presents the factor scores and their related Likert scale questions. Those scores are then normalized with the mean close to zero (as shown in Table 2). The factor scores show clear asymmetry with a kurtosis toward negative value. This indicates a larger share of respondents who reported very bad health conditions compared to those who reported very good health conditions.

\section{The variabilities within ones' self-reported physical, mental, social health conditions}

To understand the trade-off between in-home and outof-home activities on a daily basis, the distributions of time use across different physically, mentally, and 
Table 2 Profiles of the samples used in the study
Socio-demographic and Travel Activity Characteristics

Percentage/Mean

Trip engagements and travel time spent across different days of the week:

Number of trips/day from Monday-Thursday $\quad 2.52$

Number of trips/day on Friday 2.76

Number of trips/day on weekends $\quad 2.29$

$\begin{array}{ll}\text { Number of trip chains/day from Monday-Thursday } & 1.20\end{array}$

$\begin{array}{ll}\text { Number of trip chains/day on Friday } & 1.31\end{array}$

$\begin{array}{ll}\text { Number of trip chains/day on weekends } & 1.08\end{array}$

Percentage of days using motorized mode from Monday-Thursday $\quad 40.49 \%$

Percentage of days using motorized mode on Friday $\quad 37.88 \%$

Percentage of days using motorized mode on weekends $\quad 36.77 \%$

Percentage of days using public transport mode from Monday-Thursday $\quad 15.20 \%$

$\begin{array}{ll}\text { Percentage of days using public transport mode on Friday } & 14.56 \%\end{array}$

Percentage of days using public transport mode on weekends $\quad 9.55 \%$

Percentage of days using non-motorized mode from Monday-Thursday $\quad 33.23 \%$

Percentage of days using non-motorized mode on Friday $\quad 35.75 \%$

Percentage of days using non-motorized mode on weekends $\quad 32.08 \%$

Total travel time spent from Monday-Thursday (minutes) $73.97(5.14 \%)^{*}$

Total travel time spent on Friday (minutes) $\quad 75.76(5.26 \%)^{*}$

$\begin{array}{ll}\text { Total travel time spent on weekends (minutes) } & 69.35(4.82 \%)^{*}\end{array}$

Time spent for different activities on different days of the week:

Time spent for in-home mandatory activities from Monday-Thursday (minutes) $686.33(47.66 \%)^{*}$

Time spent for in-home mandatory activities on Friday (minutes) $700.00(48.61 \%)^{*}$

Time spent for in-home mandatory activities on weekends (minutes) $738.18(51.26 \%)^{*}$

Time spent for in-home leisure and maintenance activities from $302.65(21.02 \%)^{*}$

Monday-Thursday (minutes)

Time spent for in-home leisure and maintenance activities on Friday (minutes) $\quad 313.81(21.79 \%)^{*}$

Time spent for in-home leisure and maintenance activities on weekends $\quad 363.09(25.21 \%)^{*}$ (minutes)

Time spent for working/school activities from Monday-Thursday (minutes) $\quad 319.73(22.20 \%) *$

Time spent for working/school activities on Friday (minutes) $\quad 277.96(19.30 \%)^{*}$

Time spent for working/school activities on weekends (minutes) $\quad 161.99(11.25 \%)^{*}$

Time spent for out-of-home leisure and maintenance activities from $\quad 57.32(3.98 \%)^{*}$

Monday-Thursday (minutes)

Time spent for out-of-home leisure and maintenance activities on Friday (minutes) $\quad 72.46(5.03 \%)^{*}$

Time spent for out-of-home leisure and maintenance activities on weekends (minutes) $\quad 107.40(7.46 \%)^{*}$

Health indicators:

Average factor score of physical health $\quad-0.734(0.95)^{\dagger}$

$-0.113(0.91)^{\dagger}$

$[-3.46,1.97]$

$-0.106(0.96)^{\dagger}$

Average factor score of social health

$[-4.36,1.49]$

Note: Trip chain is defined as a series of trips with the starting and ending locations both at home.

*The percentages in brackets show the average proportions of time spent for travel and for each type of in-home and out-of-home activity.

† These numbers show the standard deviation and range of the reported scale of respondents' self-assessed health conditions. Since the factor score is nominal, the range is given in bracket to show the nature of the figures socially intense activities, both in-home and out-of-home activities, across different days of the week, were further examined. It can be seen from the distribution of the variables (not shown in this paper) that 


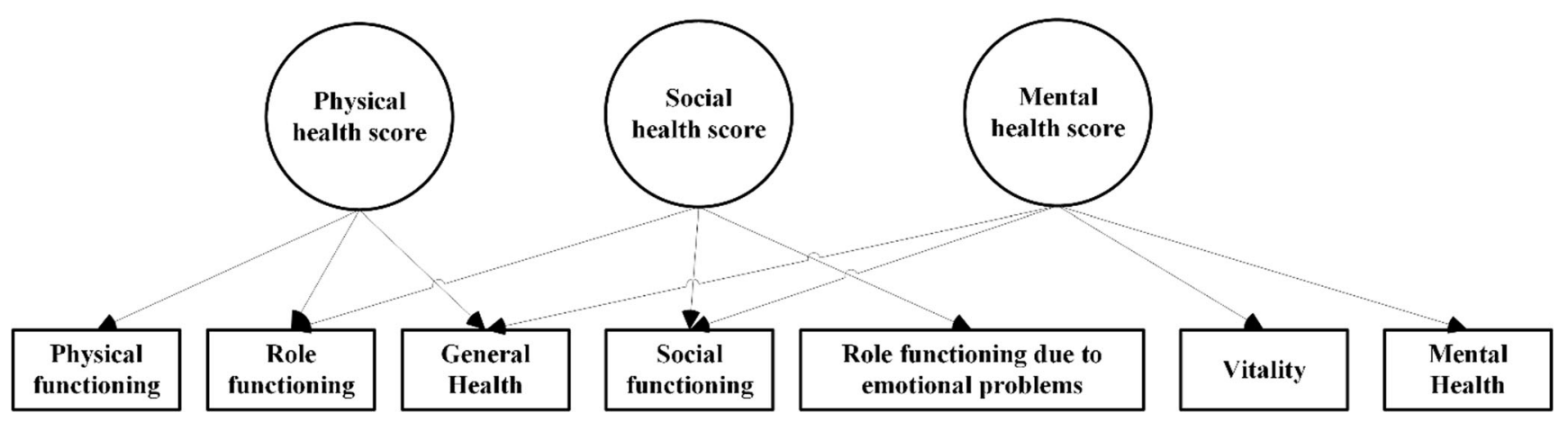

Fig. 1 The factor scores of physical, mental, and social health

individuals have longer out-of-home physical activity durations on weekdays, especially those of medium intensity, than on weekends. On contrary, the duration of out-of-home mentally medium intense activities is longer on weekends than on weekdays; but it is the other way around for out-of-home mentally high intense activities. However, there is no substantial difference between weekdays and weekends in terms of out-of-home social activity participation. It is also as expected that the individuals spend more time on in-home low intense activities (physically, mentally and socially) on weekends than on weekdays. How these time use allocations vary across different main travel mode users and across individuals with different levels of self-assessed healthiness can be seen at Figs. 2 and 3, respectively. The classification of activities and assumed level of intensities that were used in this analysis are shown in Table 3. ${ }^{1}$ Whilst the level of intensity of each physical, mental, and social activity arguably can be higher or lower as shown in Table 3, the current assumptions of activity intensity were categorised based on criteria on typical local's activity engagements that is assumed as described on the lower part of Table 3.

In terms of differences among travellers' main mode groups (see Fig. 2), those who walk and cycle most in their daily travel spend longer time on in-home low and medium intense activities (around $1.5 \mathrm{~h}$ physically, $2 \mathrm{~h}$ mentally and $2 \mathrm{~h}$ socially), such as sleeping, eating, drinking at home and relaxing activities than those who use private motorised modes and public transport. This is because they are likely to be retirees or housewives. On the

\footnotetext{
${ }^{1}$ This intensity assumption is different than activity intensity that is used in the context of physical activity and health discipline. Whilst it is acknowledged that the activity intensity is a function of various internal and external factors that influence the amount of energy used by the body per minute of activity, since the analysis is based on self-reported activity participation for $24 \mathrm{~h}$ for three-weeks, there is no way we can collect such detail metabolic intensity data for this particular analysis.
}

other hand, the ones who use private motorised modes and public transport spend more time on high intense physical activities than the non-motorised travellers (motorised travellers: $0.42 \mathrm{~h}$; public transport travellers: $0.55 \mathrm{~h}$ ). These activities include sports, participating in organization/volunteer/political activities and outdoor working/school activities. This indicates trade-off effects between the uses of physically intense travel modes with high intense activity participation at destination locations. Overall, slow mode users have a shorter duration of outof-home medium and high intense activities (physically and mentally) than private motorised modes and public transport users, though there is no such clear difference in time allocation for different types of social activities.

Figure 3, however, shows that the relationship between individuals' self-reported health conditions and their activity time use seems more confounding. Those who reported good physical health, the last quantile group $(75 \%-100 \%)$, seem to spend more time on inhome $(0.5 \mathrm{~h})$ and out-of-home $(0.06 \mathrm{~h})$ physically high intense activities than those who reported bad physical health conditions, the first quantile group $(0 \%-25 \%)$. Similarly, those who reported good mental health also have higher time use in out-of-home mentally high intense activities than those who reported bad mental health $(0.71 \mathrm{~h})$, however, they have a lower time use in out-of-home mentally medium intense activities $(-0.57 \mathrm{~h})$. From reported social health perspectives, those who reported better social health have longer time use in out-of-home socially low and medium intense activities $(1.2 \mathrm{~h})$ and shorter time use in in-home socially low and medium intense activities (1.07 h). However, some confounding relationships may be due to the differences in individual socio-demographics and residential environment. To be able to measure the impacts of different intensities of physical, mental, and social activities to the individual reported health conditions, after all other variables being controlled, a path analysis is employed in the next section. 
Fig. 2 Individual's time allocation by chosen main travel mode (Note: due to the presence of multitasking activities, the total hours of activities participation can exceed 24 h). a. participation of physically intense activities with different physical health conditions. b. participation of socially intense activities with different social health conditions. c. participation of mentally intense activities with different mental health conditions

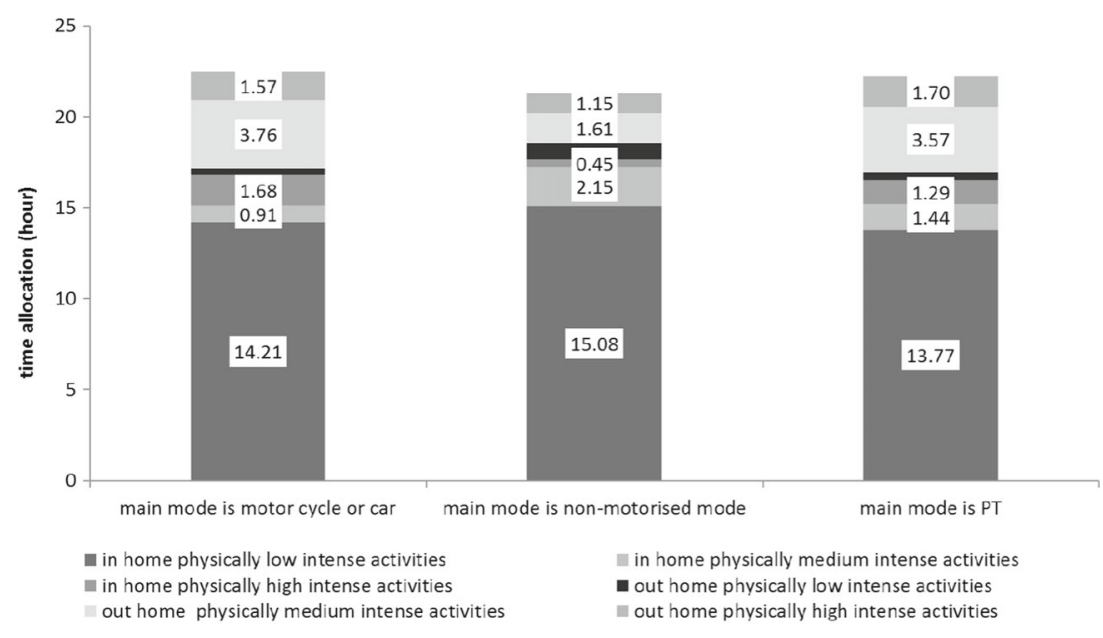

a. participation of physically intense activities

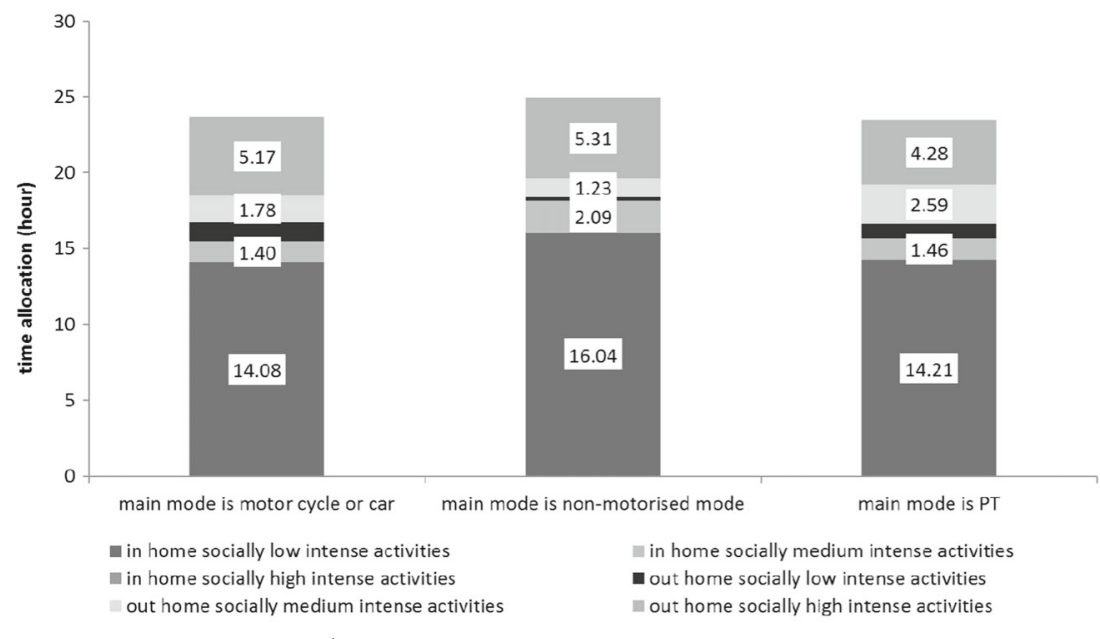

b. participation of socially intense activities

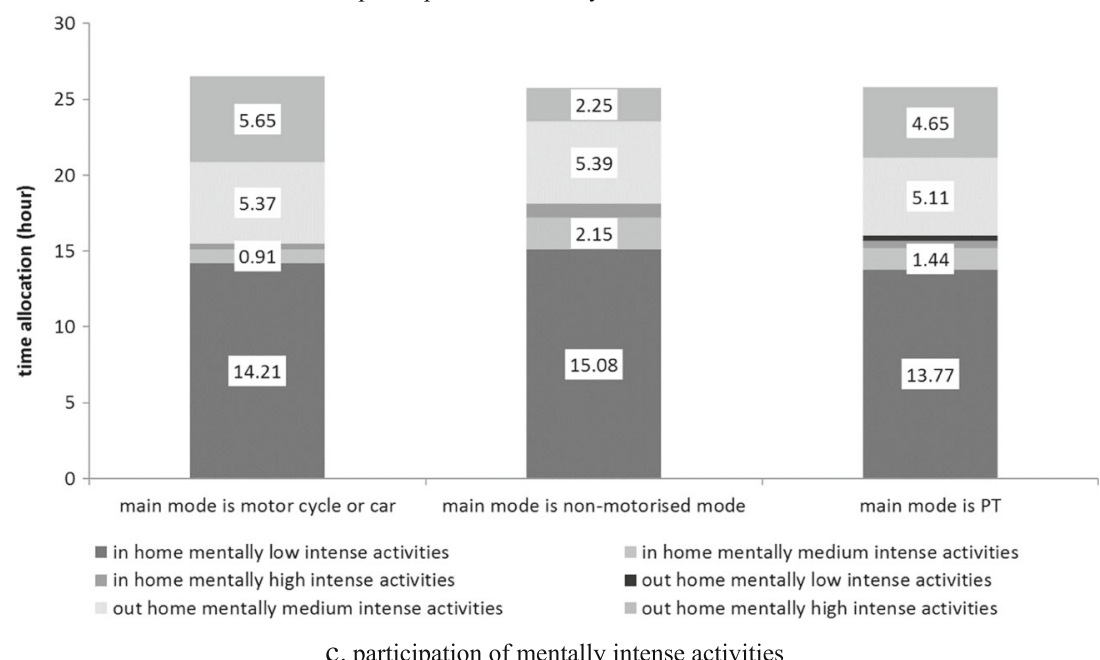

c. participation of mentally intense activities

\section{The interactions between activity participations with ones' self-reported physical, mental, social health conditions}

In order to investigate the complex relationships between in-home and out-of-home participation to the individual's self-reported physical, mental and social health conditions, a path analysis is adopted. The path model that is adopted in this study is structured as in Fig. 4 below.

In this model structure, the individual/household social demographic variables and residential environment 
Fig. 3 Individual's time allocation by different health conditions (Note: due to the presence of multitasking activities, the total hours of activities participation can exceed $24 \mathrm{~h})$

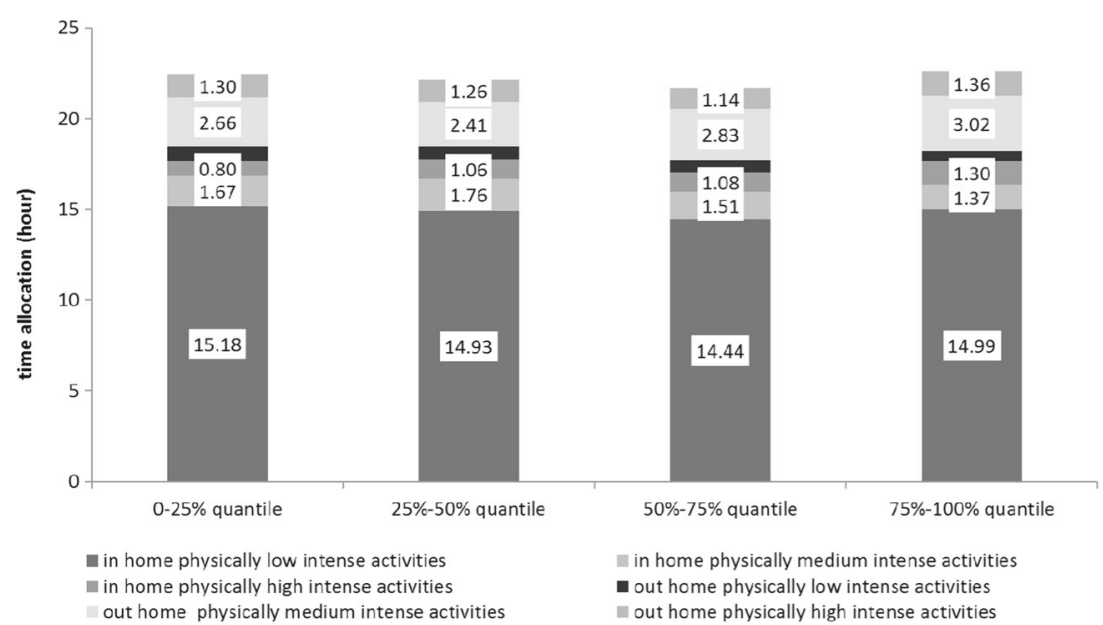

a. participation of physically intense activities with different physical health conditions

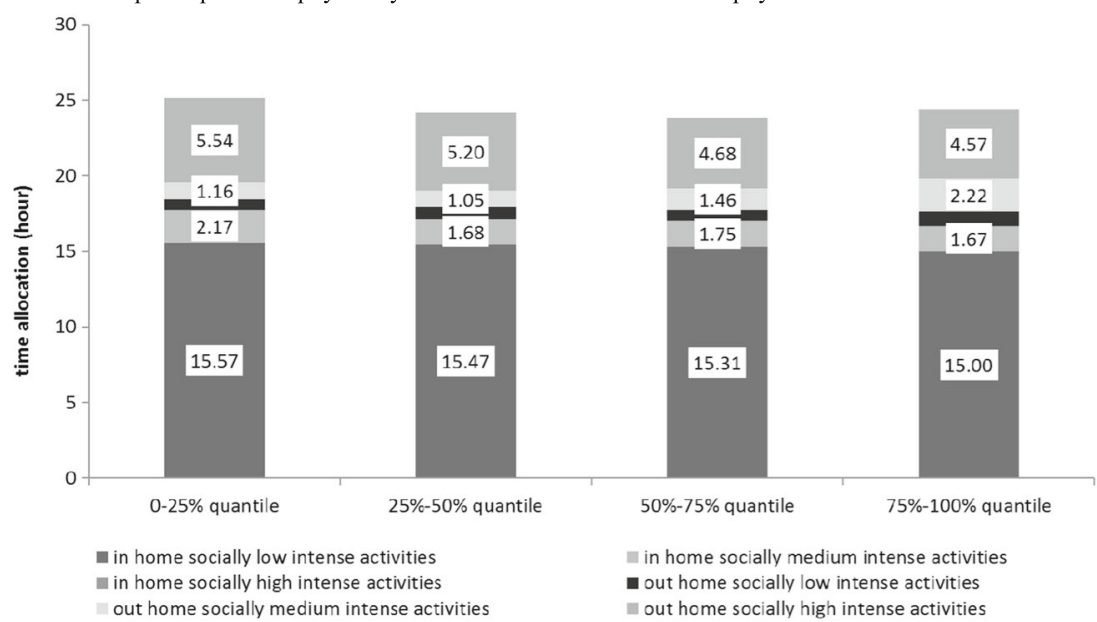

b. participation of socially intense activities with different social health conditions

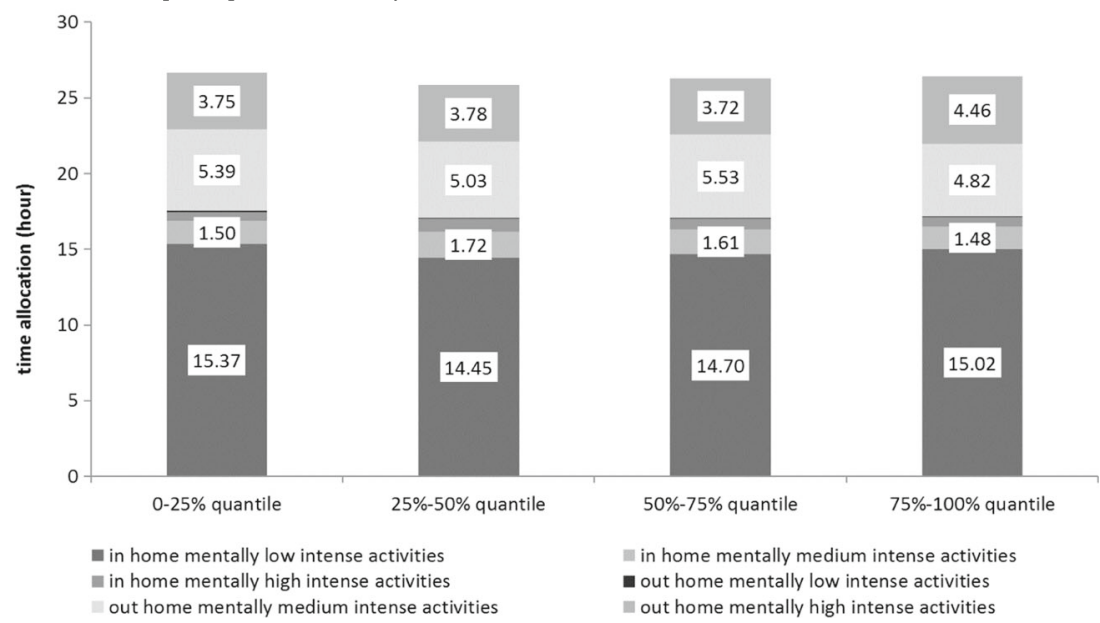

c. participation of mentally intense activities with different mental health conditions variables are treated as exogenous and they influence the time use variables. The time use groups (physical/ mental/social activities) are believed to affect individuals' health conditions (physical/mental/social health factor scores) as well as travel time. At the same time, activity duration will also impact the travel time as travel is a derived demand of activity participation. It is worth noting that the model structure takes into account the endogeneity effect. And therefore, the direct/ indirect/total effects are reported instead of the estimated coefficients (weights represented as arrows in Fig. 4). Most previous studies examined the relationship 
Table 3 Classification of activities and their intensities

\begin{tabular}{|c|c|c|c|c|}
\hline & \multirow[t]{2}{*}{ Type of Activities } & \multicolumn{3}{|c|}{ Level of intensity of engagement } \\
\hline & & Physically & Mentally & Socially \\
\hline A & Sleeping & L1 & $\mathrm{L} 1$ & L1 \\
\hline B & Personal care: taking a bath, brushing teeth, self-care etc. & L1 & L1 & L1 \\
\hline $\mathrm{C}$ & Eating and drinking at house & L1 & L1 & M1 \\
\hline $\mathrm{D}$ & $\begin{array}{l}\text { Relaxing activities, such as watching tv, listening to radio, } \\
\text { listening to music, reading newspaper/magazine/comic etc., } \\
\text { browsing internet etc. }\end{array}$ & L1 & L1 & L1 \\
\hline $\mathrm{E}$ & $\begin{array}{l}\text { Social and family activities, such as chatting with other family } \\
\text { members/friends in person or via phone, walking/biking with } \\
\text { other family members/friends, visiting relatives/friends, } \\
\text { weekly praying etc. }\end{array}$ & M2 & M2 & $\mathrm{H} 2$ \\
\hline $\mathrm{F}$ & $\begin{array}{l}\text { Household activities, such as house cleaning, cooking, baking a } \\
\text { cake, washing clothes/dishes, ironing, prepare a drink, etc. }\end{array}$ & M1 & M1 & L1 \\
\hline G & $\begin{array}{l}\text { Babysitting activities, including playing together and feeding } \\
\text { your children }\end{array}$ & H1 & H1 & M1 \\
\hline $\mathrm{H}$ & $\begin{array}{l}\text { Indoor working activities, such as working at office desk, doing } \\
\text { indoor research or experiment in laboratory, "meeting" with } \\
\text { clients at phone, etc. }\end{array}$ & M2 & $\mathrm{H} 2$ & M2 \\
\hline I & Driving vehicle to other places & $\mathrm{L} 2$ & $\mathrm{H} 2$ & $\mathrm{~L} 2$ \\
\hline $\mathrm{J}$ & $\begin{array}{l}\text { Outdoor working activities, such as operating machine or heavy } \\
\text { vehicle at outdoor environment, outdoor inspection and other } \\
\text { related activities }\end{array}$ & $\mathrm{H} 2$ & $\mathrm{H} 2$ & M2 \\
\hline K & $\begin{array}{l}\text { Sales activities from door to door, delivery and purchasing related } \\
\text { activities }\end{array}$ & $\mathrm{H} 2$ & $\mathrm{H} 2$ & $\mathrm{H} 2$ \\
\hline $\mathrm{L}$ & Indoor school activities & M2 & M2 & M2 \\
\hline M & $\begin{array}{l}\text { Outdoor school activities, including visiting zoo/museum/park, } \\
\text { camping, and other related activities }\end{array}$ & $\mathrm{H} 2$ & $\mathrm{H} 2$ & $\mathrm{H} 2$ \\
\hline $\mathrm{N}$ & Eating and drinking outside home & L2 & M2 & $\mathrm{H} 2$ \\
\hline $\mathrm{O}$ & $\begin{array}{l}\text { Shopping activities, including both local grocery shopping and } \\
\text { shopping at a shopping centre }\end{array}$ & M2 & M2 & M2 \\
\hline $\mathrm{P}$ & $\begin{array}{l}\text { Participating in organization/volunteer/political activities, such as } \\
\text { boy scout and youth/political/religious meeting activities }\end{array}$ & $\mathrm{H} 2$ & $\mathrm{H} 2$ & $\mathrm{H} 2$ \\
\hline $\mathrm{R}$ & Sport activities & $\mathrm{H} 2$ & $\mathrm{H} 2$ & $\mathrm{H} 2$ \\
\hline $\mathrm{S}$ & $\begin{array}{l}\text { Maintenance activities, including going to hospital/health } \\
\text { centre/medical doctor, bank and post office }\end{array}$ & M2 & $\mathrm{H} 2$ & $\mathrm{H} 2$ \\
\hline $\mathrm{T}$ & $\begin{array}{l}\text { Pick up and drop off children/other family } \\
\text { members/friends/business partner and others }\end{array}$ & M2 & M2 & $\mathrm{H} 2$ \\
\hline $\mathrm{U}$ & Holiday (away trip) & M2 & M2 & M2 \\
\hline V & Waiting for public transport & L2 & $\mathrm{L} 2$ & $\mathrm{~L} 2$ \\
\hline Level of intensity & Physical & Mental & Social & \\
\hline Low & not require any specific physical engagement & $\begin{array}{l}\text { not require any } \\
\text { in-purpose thinking }\end{array}$ & $\begin{array}{l}\text { not involve any specific } \\
\text { intension to interact } \\
\text { with others }\end{array}$ & \\
\hline Medium & activities with some physical engagements & $\begin{array}{l}\text { need to be aware/alert of } \\
\text { surrounding, but not } \\
\text { in intense manner }\end{array}$ & $\begin{array}{l}\text { involve activity that } \\
\text { somewhat require } \\
\text { interactions with } \\
\text { others }\end{array}$ & \\
\hline High & require intense physical engagements & $\begin{array}{l}\text { need always to be alert } \\
\text { (on-guard) and/or at } \\
\text { intensive thinking }\end{array}$ & $\begin{array}{l}\text { involve intense } \\
\text { interaction activities } \\
\text { with others }\end{array}$ & \\
\hline
\end{tabular}

Note: 1 = in-home activities, 2 = out-of-home activities; with assumption of level of intensity:

between non-motorised travel time and health (the arrows from travel time to self-reported health scores), while this study takes one step forward by considering activity durations as mediation variables as well as the trade-off effect between activity and travel time use. Therefore, the confounding health effects between an intensive activity time use and an active travel could be revealed through the direct and indirect effects of 


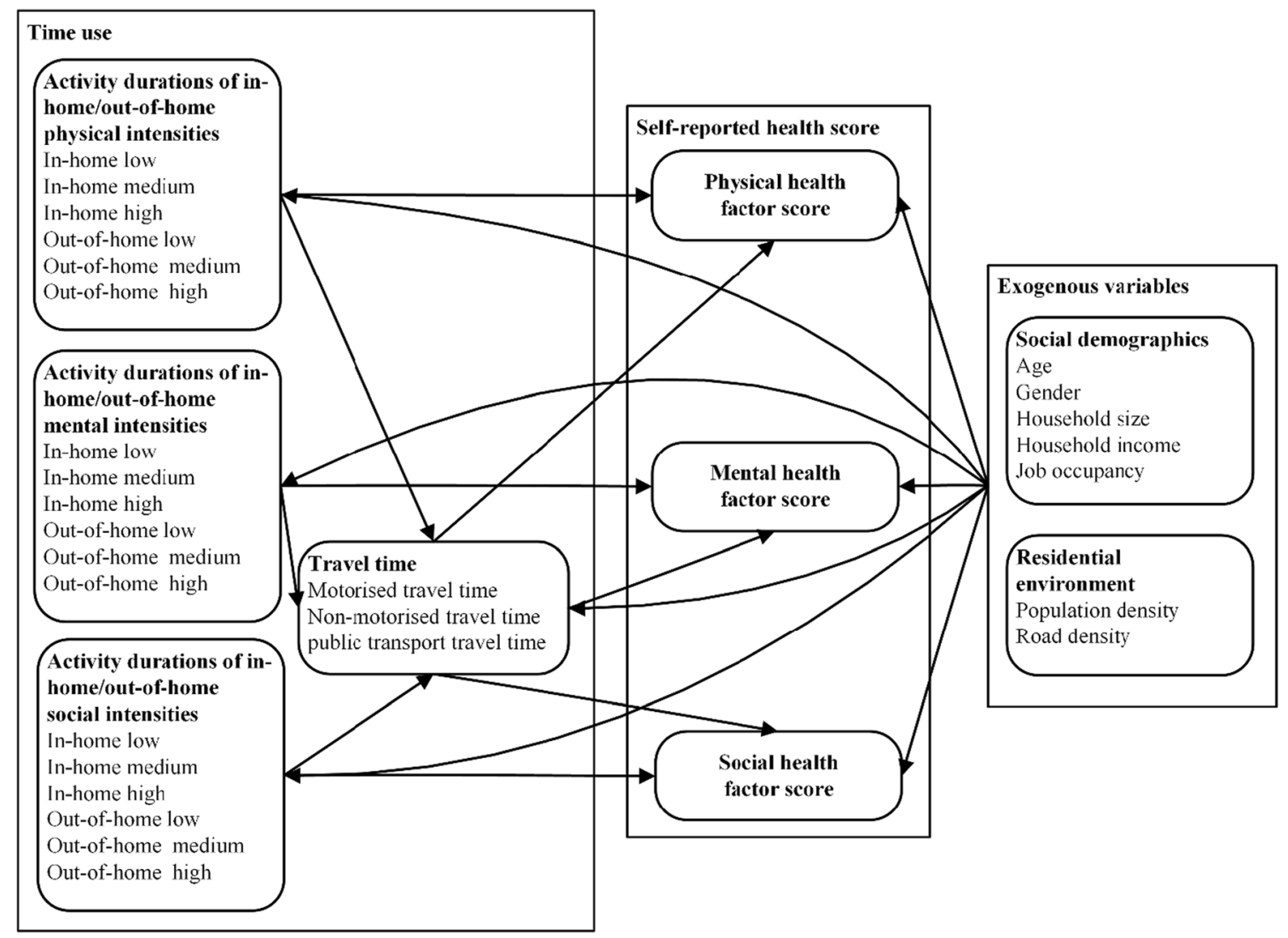

Fig. 4 The path model structure

travel time and activity time use (activity duration) on the self-reported health scores.

The model is estimated via the structural equation modelling framework. The model achieves a good model fit with $\chi^{2} / \mathrm{df}=2.73$ and root mean square error of approximation (RMSEA) as 0.056 . Table 4 presents the estimated Total effect (TE), Direct effect (DE) and Indirect effect (IE) of activity duration variables and exogenous variables on the self-reported health factor scores. Note that activity duration variables and travel time variables are now mediation variables, thus the endogeneity problem is accommodated and revealed by the indirect effects of exogenous variables on the self-reported health factor scores. Appendix Table 5 presents the estimated TE/DE/ IE of activity duration variables and exogenous variables on the travel time variables. Appendix Table 5 reveals which activity time use (physical/mental/social) has the strongest complementary/trade-off effects with travel time.

As shown in Table 4, individuals' activity participation significantly affects their self-reported health conditions, while travel time does not show any significant effects on the self-reported health conditions after controlling for the endogeneity. For self-reported physical health condition, out-of-home physically low intense activity duration positively correlates with self-reported physical health condition due to its strong DE, while the IE (activity duration influences travel time thus indirectly influences self-reported health conditions) is negative but insignificant. However, out-of-home physically medium intense activity duration shows a negative correlations self-reported physical health condition. For selfreported mental health, both in-home and out-of-home mentally high intense activities seem to be positively correlated with self-reported mental health conditions. Out-of-home mentally low intense activities show a significant DE (-0.368) but an insignificant TE. Longer out-of-home mentally low intense activities are associated with longer public transport travel time but shorter motorised travel time which indirectly improves the self-reported mental health condition. For self-reported social health, out-of-home medium intense activities/ high intense activities show a positive/negative DE but both show insignificant TE. These findings again reveal that activity participations are strongly related with individuals' self-reported health conditions but some effects are offset by the time use trade-offs between activities and travel. However, one should be aware that those findings need to be interpreted with caution. As intensity level and duration may have a non-linear effect and 
Table 4 Estimation results of the effects on self-reported health factor scores

\begin{tabular}{|c|c|c|c|c|c|c|c|c|c|}
\hline & \multicolumn{3}{|c|}{ Self-reported physical health } & \multicolumn{3}{|c|}{ Self-reported mental health } & \multicolumn{3}{|c|}{ Self-reported social health } \\
\hline & $\mathrm{TE}$ & $\mathrm{DE}$ & IE & $\mathrm{TE}$ & $\mathrm{DE}$ & IE & $\mathrm{TE}$ & $\mathrm{DE}$ & IE \\
\hline \multicolumn{10}{|l|}{ Activity duration } \\
\hline In-home low intense & -0.025 & -0.020 & -0.005 & 0.017 & 0.012 & 0.005 & -0.03 & -0.021 & -0.009 \\
\hline In-home medium intense & -0.050 & -0.048 & -0.003 & 0.025 & 0.017 & 0.008 & 1 & 1 & 1 \\
\hline In-home high intense & -0.024 & -0.025 & 0.001 & 0.031 & 0.035 & -0.004 & l & l & / \\
\hline Out-of-home low intense & $0.101 *$ & $0.124 * *$ & -0.023 & -0.238 & -0.368 & 0.129 & 0.090 & 0.080 & 0.010 \\
\hline Out-of-home medium intense & $-0.046^{*}$ & $-0.037 * *$ & -0.008 & 0.006 & -0.008 & 0.015 & 0.019 & $0.051 * *$ & -0.033 \\
\hline Out-of- home high intense & -0.060 & -0.020 & -0.040 & 0.029 & $0.039 *$ & -0.009 & -0.058 & $-0.031 * *$ & -0.026 \\
\hline \multicolumn{10}{|l|}{ Travel time } \\
\hline Non-motorised mode travel time & -0.020 & -0.020 & / & 0.090 & 0.090 & / & 0.103 & 0.103 & / \\
\hline Motorised mode travel time & -0.085 & -0.085 & / & 0.020 & 0.020 & / & 0.020 & 0.020 & / \\
\hline $\begin{array}{l}\text { Public transport travel time } \\
\text { Individual socio-demographics }\end{array}$ & 0.045 & 0.045 & / & 0.138 & 0.138 & / & 0.069 & 0.069 & / \\
\hline Female & -0.049 & 0.003 & -0.052 & -0.09 & -0.064 & -0.026 & -0.014 & 0.051 & -0.065 \\
\hline Age $<25$ & 0.186 & 0.192 & -0.006 & 0.160 & 0.130 & 0.029 & 0.153 & 0.146 & 0.007 \\
\hline Age $26-35$ & 0.060 & 0.086 & -0.026 & 0.127 & 0.084 & 0.043 & -0.044 & -0.070 & 0.025 \\
\hline Age $>55$ & $-0.723 * *$ & $-0.720 * *$ & -0.003 & -0.101 & -0.047 & -0.054 & $-0.376^{*}$ & $-0.316^{*}$ & -0.060 \\
\hline Number of household members & -0.005 & -0.005 & 0.000 & -0.007 & -0.004 & -0.003 & $0.071 *$ & $0.068 *$ & 0.003 \\
\hline Part-time or temporal worker & -0.155 & $-0.178^{*}$ & 0.024 & $-0.306 * *$ & $-0.308 * *$ & 0.002 & -0.126 & -0.174 & 0.048 \\
\hline Student & -0.013 & -0.047 & 0.034 & -0.150 & -0.019 & $-0.132 *$ & -0.012 & -0.083 & 0.071 \\
\hline Non-worker & $-0.210 *$ & -0.153 & -0.057 & -0.074 & 0.000 & -0.074 & 0.024 & 0.146 & $-0.122 *$ \\
\hline Low income & -0.107 & -0.120 & 0.013 & -0.027 & -0.009 & -0.017 & -0.040 & -0.047 & 0.006 \\
\hline High income & -0.136 & -0.144 & 0.008 & 0.222 & 0.226 & -0.005 & 0.156 & 0.126 & 0.030 \\
\hline Missing income & 0.041 & 0.024 & 0.017 & 0.152 & 0.172 & -0.021 & 0.175 & 0.126 & 0.018 \\
\hline \multicolumn{10}{|l|}{ Residential environment } \\
\hline Population density & $0.126^{* *}$ & $0.115^{*}$ & 0.011 & $0.098^{*}$ & $0.119^{*}$ & -0.022 & $0.147 * *$ & $0.119 * *$ & $0.027 *$ \\
\hline Road density & 0.003 & 0.005 & -0.002 & 0.005 & 0.005 & 0.000 & 0.001 & 0.002 & -0.001 \\
\hline \multicolumn{10}{|l|}{ Covariance of error terms } \\
\hline Self-reported physical health & $0.765^{* *}$ & & & & & & & & \\
\hline Self-reported mental health & $0.431 * *$ & & & $0.767 * *$ & & & & & \\
\hline Self-reported social health & $0.552 * *$ & & & $0.431 * *$ & & & $0.808 * *$ & & \\
\hline
\end{tabular}

Note: ** indicates that the corresponding variable is significant at $1 \%$ level, * means the corresponding variable is significant at $5 \%$ level, while no star means the corresponding variable is significant at $10 \%$ level. Grey means the corresponding variable is not significant at $10 \%$ level

reference dependency on health condition [4]. For instance, increasing duration of out-of-home physically high intense activity when the given individual already has an intensive physical activity would be less beneficial, or even physically harmful, compared to the same situation for the individual who has not exercised for a long time. In other words, how long the duration of physically high/low intense activity is considered good for physical health (reference dependent) should depend on the individual characteristics as well as their habit, past activity participation, etc.

In terms of travel time spent on the given, nonmotorised travel time, however, shows no significant correlation on self-reported health conditions, which differs from evidences from developed countries (e.g. [23, 50,
51]) who found a positive correlation between using slow modes and physical health condition. This finding may be attributed to the fact that activity time use explains most of the variations in the self-reported health conditions and travel time does not show any significant effects due to its close relationship with activity time use. In other words, activity time use should be more suitable predicting the self-reported health conditions than travel time.

In terms of socio-demographics and residential environment characteristics, older respondents (age $>55$ ), as expected, have a lower self-reported physical and social health condition than the reference age group (age 36-55), after all other variables being controlled. Older respondents in general may be more aware of social needs, thus tend to have a lower selfreported social health even when they spend the same amount 
of time on social activities as adults. Young people (age $<25$ ) shows a higher self-reported physical health condition than the reference age group (age 36-55). Those who live in large households also tend to have higher self-reported social health compared to those living in small households. Similarly, parttime workers and non-workers show lower self-reported physical health conditions compared to workers. Surprisingly, income shows no significant correlation with self-reported physical health condition, although part of income effect may be absorbed in the effect of motorised travel time. Population density positively correlates to self-reported physical health condition, indicating a potential health benefit of urban area densification in developing countries, e.g. better accessibility to hospital. Being a part-time worker would have a lower selfreported mental health condition compared to a full-time worker. Harsh work environment, unstable work time, etc. may be the underlying reason of this effect. Population density also positively correlates to all three self-reported health conditions. This indicates the potential benefits of urbanization on individuals' health conditions in general.

As can be seen from Table 4, after controlling activity time use, travel time, socio-demographics and residential environment, the remaining error terms still show considerable correlations. The three self-reported health conditions are all positively correlated with each other. Therefore, health conditions in these three dimensions should not be treated independently but positively interrelated. Other factors such as well-being, happiness, etc., which are not captured by the existing model may appear in the error terms and contribute to these positive correlations.

\section{Summary}

Using a multiday household activity-travel survey (2013 BMA dataset), this paper explored the relationship between individuals' self-reported health conditions and their activity-travel time use. The self-reported health conditions are hypothesized to be affected by individuals' activity participation pattern and usual travel mode use, described by the observed activity-travel time use in 21 consecutive days. General descriptive analysis shows clear day-to-day variability of individuals' activity-travel time use. On average, individuals only spent around 4$5 \%$ of their time on travel. In-home activities such as sleeping, in-home preparation and eating activities take more than $75 \%$ of individuals' daily time expenditure, highlighting the importance of understanding the physical activity intensity that is caused by in-home activities as well. The self-reported health conditions show, however, more confounding relationships. The trends of inhome and out-of-home activity time use may be affected by the fact that self-reported health groups consist individuals with different socio-demographics and residential environment.

The model results reveal that individuals' activity participation and socio-demographic characteristics significantly affects their self-reported health conditions, while self-reported travel time spent does not show any significant effects on the self-reported health conditions after controlling for the endogeneity (some effects are offset by the time use tradeoffs between activities and travel). Surprisingly, income shows no significant correlation with self-reported physical health condition, although part of income effect may be absorbed in the effect of motorised travel time. This study, however, did not find evidence of positive relationship between cycling and walking and self-reported physical health condition, which has been found in many developed countries. Presumably because in developing countries like Indonesia the individuals who walk and cycle are likely to be a part of economically disadvantaged and less educated groups who may have low appreciation and less awareness to oneself condition $[52,53]$.

Beside activity and travel time use factors, age and working status were found significantly affect the self-reported health conditions, regardless of respondents' gender and income. Population density also found positively correlates to selfreported respondents' health conditions, indicating benefits such as better health care in urbanised areas on individuals' health conditions in general.

However, one should also be aware of several limitations of this study. The self-reported health condition is likely to be as well related to one's well-beings, past habit, etc. and not a detailed measured medical report. Selfreported scores are reference-dependent, meaning that individuals with almost the same actual (true) health condition may judge their own health conditions very differently. Twenty-one consecutive days activity-travel participation may be enough to represent their current habit but may not describe their past habit. Thus, the self-reported health condition may also differ significantly from the true health condition due to individual's cognitive limits, that individual do not realize their health condition, and behavioural failure, that individuals themselves do know the negative effect of certain habit (e.g. smoking) on their health but do not admit it. The mismatch between self-reported health and true health may affect the estimated variable effects. It is also important that this study reveals the correlations between activity participations and individual self-reported health conditions, not necessarily the causal relationships. Thus, further interpretation need to be done with great care. Further investigation on how individual self-reported health conditions and physically active travel and activities influenced by individual attitudes and psychological characteristics would be one of plausible research directions of this study. 


\section{Appendix}

Table 5 Estimation results of the effects on travel time

\begin{tabular}{|c|c|c|c|c|c|c|c|c|c|}
\hline & \multicolumn{3}{|c|}{ Motorised travel time } & \multicolumn{3}{|c|}{ Non-motorised travel time } & \multicolumn{3}{|c|}{ Public transport travel time } \\
\hline & $\mathrm{TE}$ & $\mathrm{DE}$ & IE & $\mathrm{TE}$ & $\mathrm{DE}$ & IE & $\mathrm{TE}$ & $\mathrm{DE}$ & IE \\
\hline \multicolumn{10}{|l|}{ Phsicaly Activity duration } \\
\hline In-home low intense & 0.064 & 0.064 & l & 0.013 & 0.013 & / & 0.019 & 0.019 & / \\
\hline In-home medium intense & 0.033 & 0.033 & / & 0.048 & 0.048 & l & 0.023 & 0.023 & l \\
\hline In-home high intense & -0.013 & -0.013 & / & $-0.023 *$ & $-0.023 *$ & l & $-0.014 * *$ & $-0.014 * *$ & l \\
\hline Out-of-home low intense & 0.214 & 0.214 & / & 0.042 & 0.042 & l & -0.084 & -0.084 & l \\
\hline Out-of-home medium intense & 0.089 & 0.089 & l & 0.057 & 0.057 & l & 0.005 & 0.005 & / \\
\hline Out-of- home high intense & 0.320 & 0.320 & l & $0.426^{*}$ & $0.426^{*}$ & l & -0.103 & -0.103 & l \\
\hline \multicolumn{10}{|l|}{ Mental Activity duration } \\
\hline In-home low intense & 0.064 & 0.064 & / & 0.013 & 0.013 & 1 & 0.019 & 0.019 & l \\
\hline In-home medium intense & 0.033 & 0.033 & l & 0.048 & 0.048 & l & 0.023 & 0.023 & l \\
\hline In-home high intense & -0.013 & -0.013 & / & $-0.023 *$ & $-0.023 *$ & l & $-0.014 * *$ & $-0.014 * *$ & l \\
\hline Out-of-home low intense & $-1.037 * *$ & $-1.037 * *$ & / & $-0.161 * *$ & $-0.161 * *$ & l & $1.196^{* *}$ & $1.196 * *$ & / \\
\hline Out-of-home medium intense & 0.193 & 0.193 & / & 0.281 & 0.281 & / & -0.106 & -0.106 & / \\
\hline Out-of- home high intense & -0.090 & -0.090 & / & $-0.095 * *$ & $-0.095^{* *}$ & / & 0.007 & 0.007 & l \\
\hline \multicolumn{10}{|l|}{ Social Activity duration } \\
\hline In-home low intense & -0.082 & -0.082 & / & -0.050 & -0.050 & 1 & -0.030 & -0.030 & l \\
\hline In-home medium intense & / & / & / & / & / & 1 & / & / & l \\
\hline In-home high intense & l & 1 & l & / & l & l & / & l & / \\
\hline Out-of-home low intense & $0.390 *$ & $0.390 *$ & / & -0.051 & -0.051 & 1 & 0.108 & 0.108 & l \\
\hline Out-of-home medium intense & -0.273 & -0.273 & I & $-0.345^{*}$ & $-0.345^{*}$ & l & 0.122 & 0.122 & l \\
\hline Out-of- home high intense & -0.203 & -0.203 & / & $-0.283^{*}$ & $-0.283^{*}$ & l & 0.101 & 0.101 & / \\
\hline \multicolumn{10}{|l|}{ Individual socio-demographics } \\
\hline Female & $-0.446^{* *}$ & $-0.236 * *$ & $-0.210 * *$ & -0.036 & -0.056 & 0.020 & $0.092 *$ & $0.082 *$ & 0.011 \\
\hline Age $<25$ & 0.017 & 0.001 & 0.016 & -0.050 & 0.029 & $-0.079 * *$ & 0.003 & 0.000 & 0.003 \\
\hline Age $26-35$ & -0.038 & 0.000 & -0.038 & -0.034 & 0.000 & -0.034 & 0.048 & 0.042 & 0.006 \\
\hline Age $>55$ & $-0.433 * *$ & -0.162 & $-0.271 * *$ & 0.088 & 0.065 & 0.022 & -0.035 & 0.018 & $-0.053 *$ \\
\hline Number of household members & -0.015 & -0.008 & -0.007 & 0.002 & 0.007 & -0.005 & -0.001 & -0.003 & 0.002 \\
\hline Part-time or temporal worker & $-0.335 * *$ & $-0.240 * *$ & -0.094 & $0.121 *$ & 0.094 & 0.027 & 0.081 & -0.017 & $0.097 * *$ \\
\hline Student & 0.005 & -0.051 & 0.055 & 0.022 & -0.063 & $0.085^{*}$ & 0.077 & 0.017 & 0.061 \\
\hline Non-worker & $-0.607 * *$ & $-0.254 * *$ & $-0.354 * *$ & $0.075 * *$ & $0.030 * *$ & $0.045^{* *}$ & $-0.088 * *$ & $-0.041 * *$ & $-0.047 * *$ \\
\hline Low income & 0.036 & -0.003 & 0.040 & -0.005 & 0.001 & -0.007 & -0.052 & -0.105 & $0.053 * *$ \\
\hline High income & -0.035 & 0.015 & -0.049 & 0.089 & 0.059 & 0.030 & -0.020 & -0.044 & 0.024 \\
\hline Missing income & 0.022 & -0.015 & 0.037 & 0.059 & 0.034 & 0.025 & -0.050 & -0.101 & 0.051 \\
\hline \multicolumn{10}{|l|}{ Residential environment } \\
\hline Population density & $-0.089 * *$ & -0.031 & $-0.058 * *$ & -0.027 & $-0.061 * *$ & $0.034 * *$ & 0.016 & 0.011 & 0.006 \\
\hline Road density & $-0.009 * *$ & -0.002 & $-0.006^{* *}$ & 0.002 & -0.001 & $0.002 * *$ & $-0.004 *$ & -0.002 & $-0.002 *$ \\
\hline
\end{tabular}


Open Access This article is distributed under the terms of the Creative Commons Attribution 4.0 International License (http:// creativecommons.org/licenses/by/4.0/), which permits unrestricted use, distribution, and reproduction in any medium, provided you give appropriate credit to the original author(s) and the source, provide a link to the Creative Commons license, and indicate if changes were made.

\section{References}

1. Banister D (2008) The sustainable mobility paradigm. Transp Policy 15:73-80

2. De Hartog J, Boogaard H, Nijland H, Hoek G (2010) Do the health benefits of cycling outweigh the risks? Environ Health Perspect 118:1109-1116. doi:10.1289/ehp.0901747

3. Craig CL, Lambert EV, Inoue S, Alkandari JR, Leetongin G, Kahlmeier S (2012) The pandemic of physical inactivity: global action for public health. Lancet 380:294-305

4. Götschi T, Tainio M, Maizlish N, Schwanen T, Goodman A, Woodcock J (2015) Contrasts in active transport behaviour across four countries: how do they translate into public health benefits? Prev Med 74:42-48

5. Hallal PC, Andersen LB, Bull FC, Guthold R, Haskell W, Ekelund U (2012) Global physical activity levels: surveillance progress, pitfalls, and prospects. Lancet 380:247-257. doi:10.1016/S01406736(12)60646-1

6. U.S. Department of Health and Human Services (2008) Physical activity guidelines advisory committee report 2008. Physical activity guidelines advisory committee. Washington, DC

7. World Health Organisation (2008) The world health report 2008 primary health care (now more than ever). WHO

8. Ng M, Fleming T, Robinson M et al (2014) Global, regional, and national prevalence of overweight and obesity in children and adults during 1980-2013: a systematic analysis for the global burden of disease study 2013. Lancet 6736:1-16. doi:10.1016/S01406736(14)60460-8

9. Mueller N, Rojas-Rueda D, Cole-Hunter T, de Nazelle A, Dons E, Gerike R et al (2015) Health impact assessment of active transport policies: a systematic review. Prev Med 76:103-114

10. Sharp I, White J, Rogers L (1995) Physical activity: an agenda for action. National Forum for Coronary Heart Disease Prevention, London

11. Gorman D, Brough M, Ramirez E (2003) How young people from linguistically diverse backgrounds experience mental health: some insights for mental health nurses. Int J Men Health Nurs 12(3):194-202

12. Götschi T (2011) Costs and benefits of bicycling investments in Portland, Oregon. J Phys Act Health 8:S49-S58

13. World Health Organization (2011)Health economic assessment tools (HEAT) for walking and for cycling. Available online at: http://www.euro.who.int/_data/assets/pdf_file/0003/155631/ E96097.pdf

14. Wanner M, Götschi T, Martin-Diener E, Kahlmeier S, Martin BW (2012) Active transport, physical activity, and body weight in adults: a systematic review. AmJ Prev Med 42:493-502. doi:10. 1016/j.amepre.2012.01.030

15. Vogel T, Brechat P-H, Leprêtre P-M, Kaltenbach G, Berthel M, Lonsdorfer J (2009) Health benefits of physical activity in older patients: a review. Int J Clin Pract 63:303-320. doi:10.1111/j. 1742-1241.2008.01957.x

16. Edwards RD, Mason CN (2014) Spinning the wheels and rolling the dice: life-cycle risks and benefits of bicycle commuting in the U.S. Prev Med (Baltim) 64:8-13. doi:10.1016/j.ypmed.2014.03.015
17. Woodcock J, Tainio M, Cheshire J, O'Brien O, Goodman A (2014) Health effects of the London bicycle sharing system: health impact modelling study. BMJ 348:g425. doi:10.1136/bmj.g425

18. Xia T, Nitschke M, Zhang Y, Shah P, Crabb S, Hansen A (2015) Traffic-related air pollution and health co-benefits of alternative transport in Adelaide, South Australia. Environ Int 74:281-290. doi:10.1016/j.envint.2014.10.004

19. Musselwhite C, Avineri E, Susilo YO, Bhattachary D (2012) Public attitudes towards motorcyclists' safety: a qualitative study from the United Kingdom. J Accid Anal Prev 49:105-113

20. Musselwhite C, Avineri E, Susilo YO (2014) Legitimising risk taking: articulating dangerous behaviour on the road. Transport Plan Technol J 37(1):62-82

21. Musselwhite C, Holland C, Walker I (2015) The role of transport and mobility in the health of older people. J Transport Health 2(1):1-4

22. Andrews G, Parkhurst G, Susilo YO, Shaw J (2012) 'the Grey escape': how and why are older people using their free bus passes? J Transport Plan Technol 35:3-15

23. Woodcock J, Edwards P, Tonne C et al (2009) Public health benefits of strategies to reduce greenhouse-gas emissions: urban land transport. Lancet 374:1930-1943

24. Buliung RN, Roorda MJ, Remmel TK (2008) Exploring spatial variety in patterns of activity-travel behaviour: initial results from the Toronto travel-activity panel survey. Transportation 35:697-722

25. Susilo YO, Axhausen KW (2014) Stability in individual daily activity-travel-location patterns: a study using the HerfindahlHirschman index. Transportation 41:995-1011

26. Dharmowijoyo DBE, Susilo YO, Karlström A (2014) The day-to-day inter and intra personal variability of individual's activity space in developing country. Environ Plan B Plan Des 41:1063-1076

27. Dharmowijoyo DBE, Susilo YO, Karlström A (2015a) The day-to-day variability in Travellers' activity-travel patterns in the Jakarta metropolitan area. Transportation. doi:10.1007/ s11116-015-9591-4

28. Dharmowijoyo DBE, Susilo YO, Karlström A (2016) On complexity and variability of individuals' day-to-day discretionary activities. Transportation. doi:10.1007/s11116-016-9731-5

29. Heinen E, Chatterjee K (2015) The same mode again? An exploration of mode choice variability in great Britain using the National Travel Survey. Transp Res A 78:266-282

30. Susilo YO, Joewono TB, Santosa W (2010) An exploration of public transport users' attitudes and preferences towards various policies in Indonesia. J East Asia Soc Transport Stud 8:1202-1216

31. Susilo YO (2014) Paratransit in developing countries. Encyclopedia of transportation: social science and policy. In: Garrett M (ed) sage reference, Golson media, p 1015-1018

32. Susilo YO (2011)Paratransit, at a dictionary of transport analysis. In: button K, Nijkamp P, Vega H (eds) Edward Elgar publishing ltd., p 294-296

33. Tarigan AK, Susilo YO, Joewono TB (2014) Segmentation of paratransit users based on service quality and travel behaviour in Bandung, Indonesia. J Transport Plan Technol 37:200-218

34. Susilo YO, Joewono TB, Vandebona U (2015) Investigating the reasons underlie repetitive traffic violations behaviours among motorcyclists. J Accid Analysis Prev 75:272-284

35. Joewono TB, Tarigan AK, Susilo YO (2016) Road-based public transportation in urban areas of Indonesia: What policies do users expect to improve the service quality? Transp Policy 49:114-124. doi:10.1016/j.tranpol.2016.04.009

36. Schwanen T, Kwan MP, Ren F (2008) How fixed is fixed? Gendered rigidity of space-time constraints and geographies of everyday activities. Geoforum 39:2109-2121

37. Akar, G., Clifton, K. J, Doherty, S. T. 2011. Discretionary activity location choice: in-home or out-of-home. Transportation 38, 101122. 
38. Kang H, Scott DM (2010) Exploring day-to-day variability in time use for household members. Transp Res A 44:609-619

39. Kenyon S (2010) What do we mean by multitasking? Exploring the need for methodological clarification in time-use research. Int $\mathrm{J}$ Time Use Res 7:609-619

40. Circella, G., Mokhtarian, P. L, Poff, L. K. 2012. A conceptual typology of multitasking behaviour and polichronicity preferences. Int J Time Use Res, 9, 59-107.

41. Zhang J (2013)Urban forms and health promotion: an evaluation based on health-related QOL indicators. 13thWorld conference on transport research (WCTR)

42. Suzukamo Y, Fukuhara S, Green J, Kosinski M, Gandek B, Ware JE (2011) Validation testing of three-component model of short form-36 scores. J Clin Epidemiol 64:301-308

43. Hagströmer M, Oja P, Sjöström M (2007) Physical activity and inactivity in an adult population assessed by accelerometer. J Am Coll Sport Med 2007:1502-1508

44. Dharmowijoyo DBE, Susilo YO, Karlström A, Adiredja LS (2015b) Incorporating three-weeks' household time-use and activity diary with individual attitudes, physical activities and psychological characteristics in the Bandung metropolitan area. Transport Res A 80:231-246

45. Jones PM (2009) The role of an evolving paradigm in shaping international transport research and policy agendas over the last 50 years. In: Pendayla RM, Bhat CR (eds) travel behaviour research in an evolving world: selected papers from the 12th international conference on travel behaviour research. International Association for Travel Behaviour Research-IATBR, p 13-34

46. Hägerstrand T (1970) What about people in regional sciences? Reg Sci Assoc 24(1):7-24

47. Miller HJA (2005) Measurement theory for time geography. J Geogr Ana 37:17-45

48. Susilo YO, Dijst M (2009) How far is too far? Travel time ratios for activity participations in the Netherlands. Transp Res Rec 2134:89-98

49. Susilo YO, Dijst M (2010) Behavioural decisions of travel-time ratio for work, maintenance and leisure activities in the Netherlands. J Transport Plann Technol 33:19-34

50. Boarnet MG, Greenwald M, McMillan TE (2008) Walking, urban design, and health: toward a cost-benefit analysis framework. J Plan Educ Res 27:341-358. doi:10.1177/0739456X07311073

51. Anable J, Schuitema G, Susilo Y, Aditjandra P, Beecroft M, Nelson J (2010) Walking and cycling and socio-economic status in Scotland: analysis of statistical data and rapid review of the literature. NHS Health Scotland, United Kingdom

52. Belgiawan PF, Schmöcker JD, Fujii S (2015)Understanding car ownership motivations among indonesian students. Int J Sustain Transp 10:295-307

53. Susilo YO, Joewono TB (2016) Overview of transport and urban policies and recent travel behaviour trends on the Jakarta metropolitan area. Urban transport in emerging economies: BRICS and MINT. In: stead D, Pojani D. Springer. Forthcoming 